\title{
Vitamin K Deficiency Beyond Neonatal Period: Correspondence
}

\author{
Mandal A', Sahi PK²
}

To the Editor,

W

e read with much interest the article by Adhikari et al., published in the recent issue of your journal ${ }^{1}$ but at the same time would like to make the following comments, clarification to which would benefit the general readers of JNPS.

First: The authors mention that "Infants had received $5 \mathrm{mg}$ daily doses of vitamin $\mathrm{K}$ for minimum of 5 days or till INR was normalized". There are few evidence-based studies of how best to treat infants with Vitamin K deficiency bleeding (VKDB). The BNF (British National Formulary) for Children recommends a single intravenous dose of $250-300 \mu \mathrm{g} / \mathrm{kg}$ body weight ${ }^{2}$. The dose range of 1 to $2 \mathrm{mg}$ is found to be more than sufficient to fully correct vitamin $\mathrm{K}$ deficiency in infants aged up to 6 months. Higher doses offer no advantage in efficacy or speed of reversal of even a severe coagulopathy due to a nutritional vitamin $\mathrm{K}$ deficiency ${ }^{3}$.

Second: Three (18.7\%) infants with VKDB related ICH (Intracranial hemorrhage) had received vitamin $\mathrm{K}$ injection at birth. This is very surprising as a recent systematic review [4] has demonstrated a $98 \%$ reduction (95\% Cl 90 to 100\%) in the incidence of late VKDB following $\mathrm{IM}$ vitamin $\mathrm{K}$ prophylaxis. Though it is mentioned that "other" causes of $\mathrm{ICH}$ including liver disease were excluded in the studied children, this raises the suspicion whether secondary causes of vitamin $K$ deficiency such as cystic fibrosis, a1-antitrypsin deficiency, etc were missed.

Reply from the authors: We thank Dr. Anirban Mandal and Dr. Puneet Kaur Sahi for giving us opportunity to give more incites regarding our paper ${ }^{1}$.

Firstly: Earlier studies and case reports ${ }^{5}$ have mentioned the use of higher dose of parenteral vitamin K ( $5 \mathrm{mg} /$ day). Higher doses 5-10 $\mathrm{mg}$ is used in older children and adults without dose related adverse events. Most infants had responded with 1 or 2 doses of vitamin $\mathrm{K}$ as described in the case series. Multiple doses were only used in the children with secondary Vitamin $\mathrm{K}$ deficiency. We agree that recent guideline recommend single dose intravenous dose of 250-300 $\mu \mathrm{g} /$ $\mathrm{kg}$ body weight or 1-2 $\mathrm{mg}$ in infants to correct vitamin $\mathrm{K}$ deficiency ${ }^{3}$.

Second: Possibility of secondary causes of vitamin K deficiency with chronic diarrhea such as cystic fibrosis, a1-antitrypsin deficiency, etc couldn't be rule out. Besides the use of antibiotic use in preceding week and maternal vitamin K status was also not known. Retrospective

${ }^{1}$ Dr. Anirban Mandal Department of Paediatrics, Sitaram Bhartia Institute of Science and Research, New Delhi, India. ${ }^{2} \mathrm{Dr}$. Puneet Kaur Sahi, Department of Paediatrics, Kalawati Saran Children's Hospital, New Delhi, India.

\section{Address for correspondence \\ Dr. Anirban Mandal \\ E-mail: anirban.nrs@gmail.com}

\section{How to cite}

Mandal A, Sahi PK. Vitamin K Deficiency Beyond Neonatal Period: Correspondence. J Nepal Paediatr Soc 2017;37(3):300-301.

doi: http://dx.doi.org/10.3126/jnps.v37i3.18340

This work is licensed under a Creative Commons Attribution 3.0 License. 
study with small sample size could have contributed for the higher $(18.7 \%)$ report of $\mathrm{VKDB}$ related $\mathrm{ICH}$ in the case series. There are studies indicating reports of $\mathrm{ICH}$ in infants who have received vitamin $\mathrm{K}^{6}$. Large multicenter randomized controlled trial about vitamin $\mathrm{K}$ status in infants and VKDB is necessary in future.

\section{References}

1. Adhikari S, Gauchan E, Malla T, Sathian B, Rao KS. Intracranial Hemorrhage Caused by Vitamin K Deficiency Beyond Neonatal Period. J Nepal Paediatr Soc 2017;37(1):104-107. DOI: http://dx.doi. org/10.3126/jnps.v37i1.16301

2. Paediatric Formulary Committee. BNF for Children 2007. London: BMJ Publishing Group, RPS Publishing and RCPCH Publications; 2007.

3. Shearer MJ. Vitamin K deficiency bleeding (VKDB) in early infancy. Blood Rev 2009;23(2):49-59. DOI: 10.1016/j.blre.2008.06.001

4. Sankar MJ, Chandrasekaran A, Kumar P, Thukral A, Agarwal R, Paul VK. Vitamin K prophylaxis for prevention of vitamin $\mathrm{K}$ deficiency bleeding: a systematic review. J Perinatol 2016;36 Suppl 1:S2935. DOI: 10.1038/jp.2016.30.

5. Grillo E, Silva RJ, Filho JH. vitamin K, intracranial hemorrhage, hemorrhagic disease of the newborn, vitamin K deficiency.J Pediatr (Rio J) 2000; 76(3): 2336.

6. Unal, E., Ozsoylu, S., Bayram, A. Ozdemir MA, Yilmaz $E$, Canpolat $M$ et al. Intracranial hemorrhage in infants as a serious, and preventable consequence of late form of vitamin K deficiency: a selfie picture of Turkey, strategies for tomorrow. Childs Nerv Syst 2014;30: 1375. DOI: doi.org/10.1007/s00381-014-2419-2. 